\title{
Anxiety in craniomandibular disorders and bruxing behavior patients: The role of pain in single and multiple sites and severity of bruxing behavior. Part I: Inclusion of the extreme behavior group and report of preliminary psychological data on anxiety
}

\author{
Ansiedade em pacientes com distúrbios craniomandibulares e \\ bruxismo: O papel da dor em locais únicos e múltiplos e severidade \\ do bruxismo. Parte I: Inclusão do grupo extremo e relato de dados \\ psicológicos preliminares
}

Molina $\mathrm{OF}^{1}$, Sobreira $\mathrm{MA}^{2}$, Tavares $\mathrm{PG}^{3}$, Dib JE${ }^{4}$, Aquilino $\mathrm{RN}^{5}$

\begin{abstract}
SUMMARY
Objective: To assess the level of anxiety in patients with bruxing behavior and craniomandibular disorders (CMD). Methods: We evaluated 108 patients with bruxism and CMD, 20 patients with mild bruxism, 32 with moderate, 36 with severe and 20 extreme. We used the Test of Manifested Anxiety of Taylor (TMAS), clinical examination, a questionnaire of clinical-epidemiological data and the criteria for CMD: clinical examination, palpation of muscle and joints, the Visual Analogue Scale for pain. We also introduced an empirical scale to classify the level of anxiety as absent or mild, moderate, severe and very severe. Results: The level of anxiety increased from the mild to the moderate, severe, and extreme bruxing groups but the difference was only significant from the severe to the other three groups of bruxers $(p<0.05)$. The level of pain also increased from the mild to the extreme group of bruxers but the difference was not statistically significant. When we analyzed the site of pain, there were differences but not significant $(p<0.07)$. The correlation's painful sites anxiety, severity of bruxing behavior - anxiety, and severity of bruxism number of painful sites, were significant $(p<0.02, p<0.05$, and $p<0.0001$, respectively). Conclusion: Using our empirical criteria, levels of moderate and severe anxiety predominated in the group of $108 \mathrm{CMD}$ and bruxing behavior patients.
\end{abstract}

\section{Keywords: Craniomandibular disorders, Bruxism, Anxiety.}

Citation. Molina OF, Sobreira MA, Tavares PG, Dib JE, Aquilino RN. Anxiety in craniomandibular disorders and bruxing behavior patients: The role of pain in single and multiple sites and severity of bruxing behavior. Part I: Inclusion of the extreme behavior group and report of preliminary psychological data on anxiety. Rev Neurocienc 2006; 14(1):023-030.

Trabalho realizado: Faculdade de Odontologia da UNIRG, Gurupi, Tocantins.

1 - Mestre em Ciências, Post Graduate Achievement AES, Chicago, Post Doct em Dor Orofacial U. Harvard, USA; Professor Associado Convidado UNIRG-Odontologia: Oclusão, Dor Orofacial, Estomatologia, Gurupi-Tocantins.

2 - Mestre e Doutor em Ortodontia, Professor de Ortodontia da UNIRG, Gurupi, Tocantins.

3 - Doutor em Patologia Bucal UNESP, Professor de Patologia UNIRG, Consultor Programa de Câncer Bucal Secretaria da saúde do Estado do Tocantins.

4 - Especialista em Cirurgia Buco Maxilo Facial, Mestrado em Ciências da Saúde, Professor Adjunto Fisiologia Faculdade de Odontologia UNIRG.

5 - Especialista em Radiologia Odontológica FOB-USP, Mestre em Radiologia Odontologia UNICAMP, Doutorando em Radiologia Odontológica UNICAMP.

Correspondent author: Omar Franklin Molina, DDS, MD, PA, Post Doct - Faculdade Odontologia UNIRG; Centro de Dor Orofacial e Distúrbios Temporomandibulares - Avenida Pará 1544; Centro, Gurupi, Tocantins CEP 77400-000 - Email: omarmolinatinoco@yahoo.com 


\section{RESUMO}

Objetivo: Avaliar o nível de ansiedade em pacientes com distúrbios craniomandibulares (DCM) e bruxismo. Método: Avaliamos 108 pacientes com bruxismo e DCM, 20 com bruxismo leve, 32 com moderado, 36 com grave e 20 com extremo. Usamos o Questionário de Ansiedade Manifesta de Taylor (TMAS), um questionário clínicoepidemiológico sobre bruxismo, e os critérios para DCM: exame clínico de músculos, articulação e movimentos mandibulares e uma escala visual analógica para dor. Introduzimos uma escala empírica para classificar a ansiedade como ausente-leve, moderada, grave e muito grave com base nas 28 questões positivas do TMAS. Resultados: O nível de ansiedade aumentou do grupo com bruxismo leve para moderado, grave e extremo, mas a diferença foi somente significante do grupo extremo para os outros três grupos $(p<0.05)$. Os resultados mostraram que o nível de dor aumentou do grupo leve para os outros três grupos, mas a diferença não foi estatisticamente significante. Quando analisamos os pacientes com DCMs e bruxismo segundo os locais de dor, houve diferenças porém não significante $(p<0.07)$. Verificamos que foram significantes as correlação: locais de dor e nível de ansiedade $(p<0.02)$, severidade do bruxismo e ansiedade $(p<0.05)$ e severidade do bruxismo e número de locais de dor $(p<0.0001)$. Conclusão: Níveis de ansiedade moderada/severa predominaram nos 108 pacientes com bruxismo.

\section{Unitermos: Transtornos craniomandibulares, Bruxismo, Ansiedade.}

Citação. Molina OF, Sobreira MA, Tavares PG, Dib JE, Aquilino RN. Ansiedade em pacientes com distúrbios craniomandibulares e bruxismo: O papel da dor em locais únicos e múltiplos e severidade do bruxismo. Parte I: Inclusão do grupo extremo e relato de dados psicológicos preliminares.Rev Neurocienc 2006; 14(1):023-030.

\section{INTRODUCTION}

Oral jaw behaviors are a general term used to describe a psychophysiological disorder that has been neglected in the stomatognathic literature during many years. Even though clinical practice and research concentrate their efforts in the study of bruxing behavior, actually, there are many other oral jaw habits which contribute to increase muscle activity and thus may cause severe damage to the masticatory system including muscles, teeth, cheeks, tongue, lip, temporomandibular joints (TMJ), and muscles of the head and neck. Anxiety may be a behavioral response to a situation of stress and tension or the manifestation of a disease that may be the problem per se or even the result of a pathological personality. In some cases, anxiety may be a symptom or disorder and as such, may cause a disease. Rollo May ${ }^{1}$, writing his book on the meaning of anxiety, reports that to have a disease is a way of solving out a situation of conflict. May's concept of anxiety is in agreement with the concept of bruxing behavior which is frequently defined as a mechanism of somatization, a situation of conflict and/or the result of unresolved rage, frustration and hostility.

Anxiety can also be viewed as a symptom and as such, should be considered as the result of a situation of conflict which is not being solved out or channeled properly by the individual. Anxiety and bruxism should be considered as somatic manifestations, forms of body language that cannot be understood by the individual. When bruxing behavior is severe, it should be readily considered as a severe somatic disease with obvious symptomatic manifestations in the masticatory system, muscles of the head and neck, cranial bones, joints, teeth and periodontal membrane. It seems evident that when the individual is unable to escape to a situation of conflict, fear can be converted into anxiety and psychosomatic changes can occur together with anxiety. This point of view is supported by two clinical observations:

1. Anxiety, bruxing behavior and Craniomandibular Disorders (CMD) sign and symptoms, occur together in most patients;

2. If the severity of anxiety increases, the severity of $\mathrm{CMD}$ increases concomitantly.

\section{Review of the literature: Craniomandibular dis- orders}

Craniomandibular disorders (CMD) is a collective term introduced in the literature within the last twenty years and designates a group of disorders including bruxing behavior, temporomandibular disorders (TMD), masticatory pain and myofascial pain dysfunction syndrome of the face, head and neck. Headache pain has been included in this categories there increasing evidence that this disorder predominates in patients presenting with $\mathrm{CMD}^{2}$. Some of the most common signs and symptoms of CMD include headache, facial pain, bruxing behavior, cervical pain, functional disorders of the TMJ, altered jaw movements during function local, referred pain and tenderness to palpation which predominate in those patients. The relationships between bruxing behavior, CMD and headache are becoming more clearly in the last few years. Moderate and severe forms of bruxing behavior can cause, fatigue, spasm and pain in the cranial and cervical muscles which in turn result in headache ${ }^{3}$.

Severe bruxing behavior is more likely to cause internal joint disorders including capsulitis that in turn can lead to referred pain to the head and neck. 


\section{Subgroups of Craniomandibular Disorder patients}

Studies carried out in the last twenty years suggest that different subgroups of CMD patients do exist ${ }^{4}$ and recognizing this different groups has clinical importance since management should be directed at some sign and symptoms which are characteristics of each specific subgroup. According with this, subgroups of patients presenting capsulitis, retrodiskal pain, disk attachment pain, arthralgia, disc displacement with and without reduction, temporary locking, and osteoarthritis-osteoarthrosis can be observed. Other subgroups of CMD patients include those presenting myofascial pain, masticatory pain, pain in multiple sites, headaches, referred pain to the teeth and bone (from trigger points), neuropathic pain, neurogenic pain, atypical facial pain and psychogenic pain.

Patients presenting a combination of different disorders are not rare in clinical practice. For instance, vascular pain or migraine, myofascial pain, internal joint derangements and masticatory pain can be seen in a single patient in the clinical practice. Research has consistently demonstrated that even bruxers can be classified in CMD patients presenting bruxing behavior with pain and without pain ${ }^{5}$, bruxism occurring during sleep periods, bruxism and depression and bruxism with destructive sign and symptoms ${ }^{6}$. Frequent and non-frequent4, heavy and light and mild, moderate and severe bruxing behavior groups, have also been described ${ }^{2,3}$.

\section{Subgroups of bruxing behavior patients}

That different subgroups of bruxers can be identified was observed by the pioneering investigation of Olkinuora carried out in $1972^{7}$. He found that bruxers could be classified as strain and non-strain bruxers. The study carried out by Dao et $\mathrm{al}^{5}$ was the first investigation to demonstrate a clear contrast in the level of pain reported by the groups of bruxing behavior patients. They also demonstrated that those bruxers presenting pain and depression had a higher level of pain as compared to those presenting pain but no depression. One study², about the prevalence of specific internal joint disorders in patients presenting with mild, moderate and severe bruxing behavior found that the prevalence of specific internal joint disorders increased with the severity of bruxing behavior indicating that increased neuromuscular loading in the TMJ associated with more severe bruxing behavior is an important factor causing the progression of the disorder and more severe pain. Kampe et $\mathrm{al}^{4}$, carried out a clinical and epidemiological study and reported that bruxers are not a homogeneous group as those presenting with more frequent bruxing behavior demonstrated higher levels in the somatic anxiety, psychic anxiety and muscular tension scales as compared to the less frequent bruxers.

\section{Anxiety}

Rollo May ${ }^{1}$ defines anxiety as the psychic component of any potential or real disease. He further suggests that the more manifest the anxiety is and the greater its manifestation as a neurotic behavior, the less serious the organic disease. In his conceptualization of anxiety, May views symptoms as very frequent modes to stop anxiety there fore symptoms are considered as "structured anxiety". On the other hand as anxiety is the more common characteristic of a neurotic disease, it can also be conceptualized as a displacement mechanism of an overwhelming ego.

Anxiety is not the same as stress although many people including psychologists use the same terms to mean the same thing. However, stress is a physical term take from the Engineering Sciences whereas anxiety means something internal to the individual that can cause both internal and external reactions. It is just a complex psychological and internal phenomenon more difficult to see and describe. Qualitatively, stress is a very different phenomenon. Is not the same to ask somebody how much tension (physical) or stress he experiences than to ask the level of anxiety he or she is felling. Freud ${ }^{8}$ studying anxiety in many patients concluded that a symptom in most cases replaces anxiety. This statement indicates that in CMD patients, many sign and symptoms in many anatomic areas and severe bruxing behavior may be replacing anxiety. We assume that by using the Taylor Manifest Anxiety Scale (TMAS) in bruxers and CMD patients, different levels of anxiety may be observed.

It has been reported that persistent muscular tension leads to pain and this cycle of events causes the TMD $^{9}$. One study indicates that groups of myofascial pain patients demonstrate higher levels of anxiety as compared to control subjects and that their anxiety is the cause of the symptoms. Greene et $\mathrm{al}^{10}$, observed an increased level in the psychastenia scale of the MMPI (Minnesota Multiphasic Personality Index) in myofascial pain dysfunction syndrome (MPDS) patients as compared to control subjects. This scale is related to some psychological areas including anxiety and fear, low self esteem, doubts about self competence, sensibility with no specific cause, altered mood and immobility. Researchers found that only half of the patients showed symptoms of anxiety as measured by the MMPI. Malow et $\mathrm{al}^{11}$, assessed the levels of anxiety using the STAl (State Trait Anxiety Inventory) and reported higher levels of anxiety in MPDS patients as compared to normal controls, but the difference was not significant. It could be that those presenting the highest levels of anxiety as it is commonly the case, formed a subgroup of individuals which is behaviorally and psychologically different as compared to the whole group. It has been observed that CMD patients as a group are more anxious that the general population and that anxiety is a psychophysio- 
logical phenomena which lowers the pain threshold in individuals presenting with pain, that bruxing behavior is basically an anxiety disorder and that anxiety is a characteristic of acute pain patients whereas depression is the main feature of chronic temporomandibular disorder (TMD) patients with pain.

\section{Anxiety and craniomandibular disorders}

In the last few years, many studies comparing levels of psychopathology between CMD patients and individuals of a normal population have been carried out primarily to provide new data about etiology and psychophysiologic characteristics of these patients. For instance, Mutlu et $\mathrm{al}^{12}$, used psychometric instruments including STAl to gather psychological data and assess a group of dental students and "normal individuals" and reported a prevalence of $17 \%$ CMD and a level of anxiety of about 0.883 in the group of CMD students and 0.781 in the normal control group, but the difference was not statistically significant. Additionally, Phillips et $\mathrm{al}^{13}$, evaluated a group of 233 CMD patients presenting with acute conditions. Patients were assessed at baseline and six months later. Researchers found that anxiety disorders were observed in $48.45 \%$ chronic CMD and $33.25 \%$ acute CMD cases respectively. Meldolesi et a ${ }^{14}$ evaluated another group of TMD patients, used DMS-IV (Statistical Manual for Mental Disorders) criteria for anxiety/ depression and the Hamilton Scale to evaluate anxiety and found that TMD cases demonstrated higher scores in the somatic anxiety subscale as compared to psychiatric patients and the difference was statistically significant because $p<0.05$. One study ${ }^{5}$, investigated a group of 10 subjects who participated in a polysomnographic study of nocturnal bruxing behavior and a group of 61 myofascial pain patients and reported a prevalence of $42.1 \%$ emotional tension in the group of bruxers whereas $83.6 \%$ of myofascial cases reported that they felt tense. These studies as a whole suggest that anxiety/emotional tension is an important factor observed in subgroups of CMD patients.

\section{Muscular tension}

Muscular tension in the orofacial region can be observed as a localized manifestation of anxiety, as the result of increased muscle activity associated with a number of oral jaw habits or related to some levels of bruxing behavior. It is known that anxiety causes muscle hyperactivity localized to the lower back, cervical and facial regions. We believe that a combination of oral jaw habits and anxiety are the most common factors related to masticatory hyperactivity which in some cases can cause signs and symptoms including masticatory pain and sometimes trigger points and then myofascial pain dysfunction syndrome. Heigberg et $\mathrm{al}^{15}$, defend the notion that stress perceived by the psychic apparatus is mediated by the central nervous system and can lead to hyperactivity of the masticatory muscles causing micro trauma to the muscles, tenderness to palpation and jaw dysfunction which are characteristics of myofascial pain patients. Mutlu et $\mathrm{al}^{12}$ points out that emotional states including anxiety can encourage the development of muscular tension, CMD and muscular pain. They further emphasized that persistent muscular tension leads to pain and this sequence of events ultimately result in the TMD.

Eggen ${ }^{16}$ used a questionnaire and clinical examination to assess myofascial pain patients whom he compared to a control group and found that myofascial pain patients more frequently reported a higher frequency of shoulder, back, arms and leg pains. He then suggested that the increased facial muscles tension observed in such MPDS patients was just a component of a more general increased muscular tension and the level of such tension depend on the severity of anxiety. Some muscles adapt easily to physiologic exercise and by doing so they become more resistant to the noxious effects of repeated bouts of the same exercise. The muscular tension developed by some bruxers can be in the range of adaptation of the system (mild bruxers). However, in other cases the neuromuscular tension developed by some patients may pose some difficulties for adaptation and therefore sign/ symptoms can develop (moderate and severe bruxers). Even the protective mechanism developed by some muscles in the case of moderate and severe bruxism are not adaptive in nature as they result in increased tension and contracture associated with pain, development of trigger points and sustained painful contraction.

One research ${ }^{4}$ assessed a group of 29 longstanding bruxers/CMD patients. They used the Karolinska Scales of Personality (KSP) to gather psychological data and we summarized their results as follows:

1. As a group, bruxers demonstrated higher values in the scale assessing muscular tension that in turn was correlated with headache pain, neck and back pain.

2. Chronic bruxers described themselves as more predisposed to anxiety and scored higher in the scale measuring somatic anxiety, suggesting that they had more predispositions to present with pain in multiple sites. Because the relationships between anxiety and subgroups of bruxing behavior patients, severity of pain and pain in single and multiple sites in bruxers and anxiety and painful sites, are not well defined, the goals of this study are to assess the level of anxiety in the whole group of CMD and bruxing behavior patients, in subgroups of those patients, and to introduce the "extreme CMD and bruxing behavior group" in the literature reporting its level of anxiety.

\section{MATERIALS AND METHODS}

Data for the study were gathered from a group of 108 CMD cases referred consecutively to a Center for the Study of CMD and bruxing behavior in the years of 
2004 and 2005 to the University of Gurupi, Dental School, State of Tocantins. Of these 108 patients, 20 demonstrated mild bruxing behavior-CMD, 32 exhibited moderate bruxing behavior-CMD, 36 presented with severe bruxing behavior-CMD and 20 demonstrated extreme bruxing behavior and signs/symptoms of CMD. The following procedures were used to gather clinical/ psychological/ diagnostic data:

1. Clinical examination of joint and muscles, palpation of all masticatory muscles and assessment of jaw movements;

2. Use of the Visual Analogue Scale (VAS) to assess the severity of pain;

3. History of sign and symptoms including location, severity, chronic and clinical characteristics of the pain;

4. Questionnaires to assess presence and severity of bruxing behavior and other oral jaw habits;

5. Biomechanical tests to assess the presence of internal joint derangements;

6. Classification of the occlusion;

7. Criteria published in the literature to include patients as presenting with CMD in the study;

8. Two questionnaires, one to evaluate quality of life and other to evaluate type A personality;

9. The Beck Depression Inventory (BDI) for depression, the Taylor Manifest Anxiety Scale (TMAS) for anxiety;

10. The Cook Medley questionnaire to assess hostility and a set of questionnaires from the MMPI to evaluate hysteria, hypochondria and somatization;

11. The Becker-Saunders questionnaire to assess physical/sexual maltreatment and a questionnaire to assess guilt.

Following the use of this battery of tests, patients were grouped in those presenting with no bruxing behavior and $\mathrm{CMD}$, mild bruxing behavior and CMD, moderate bruxing behavior and $\mathrm{CMD}$, severe bruxing behavior and $\mathrm{CMD}$, and extreme bruxing behavior and CMD. Criteria to allocate patients as presenting mild, moderate, and severe bruxing behavior and CMD were published previously ${ }^{2}$. However, the novelty of this study is that we report for the first time in the literature about CMD, orofacial pain and bruxing behavior the presence and some characteristics of the extreme bruxing behavior group and its clinical implications.

Criteria for inclusion in any of these four groups are explained briefly:

1. No bruxing behavior: Those reporting/presenting 0-2 signs or symptoms of bruxing behavior

2. Mild bruxing behavior: Those reporting/presenting 3-5 signs/symptoms of bruxing behavior
3. Moderate bruxing behavior: Those reporting/presenting 6-10 signs and symptoms of bruxing behavior

4. Severe bruxing behavior: Those reporting/presenting 11-15 signs and symptoms of bruxing behavior

5. Extreme bruxing behavior: Subjects reporting 16 or more signs and symptoms of bruxing behavior.

\section{Anxiety assessment:}

We used only the 28 affirmative questions of the TMAS $^{17}$ self reported questionnaire. In order to compare our data with previous studies we designed a scale on the severity of anxiety as reported by patients, as follows: 0-7 score in anxiety $=$ none or mild anxiety; $8-14$ positive responses $=$ moderate anxiety; $15-21$ positive responses in the questionnaire = severe anxiety; $22-28$ positive responses in the questionnaire $=$ very severe anxiety.

\section{Statistical analysis}

Statistical analysis included the use of the following tests: Smirnov-Kolmogorov to assess the normality of the distributions, Bartlett test to evaluate the equality of variances, Qui-square to study differences in proportions, Pearson correlation test to assess the strength of some correlations, parametric and non parametric ANOVA.

\section{RESULTS}

This comprehensive protocol to assess patients including multiple clinical and psychological tests was developed during many years and is used in every single patient seeking diagnosis and treatment of CMD. Such a protocol allows us multiple diagnosis/treatment and it would enable us to report multiple findings of interest. However, we believe that it would be irrelevant to display multiple data for example on depression, hostility, anxiety, somatization and guilt on a single paper that would be confusing to the reader.

The results of this study are presented in tables 1-6. Table 1 presents sociodemographic data of $108 \mathrm{CMD}$ and bruxing behavior patients. Table 2 presents data about anxiety in the mild, moderate, severe and extreme group of bruxers. Table 3 shows data on the level of pain in the four subgroups of patients and table 4 shows data about the level of anxiety in the groups of CMD and bruxing behavior patients presenting with different painful sites. Table 5 shows specific data on specific pair of variables and Table 6 displays data on levels of anxiety in 108 bruxers and CMD patients.

Group ages: The mean ages of the groups shown in table I were about 33.0, 30.65, 33.2, 34.5 and 33.33 years old in the whole group of CMD and bruxing behavior, mild, moderate, severe and extreme groups respectively. The mean age of the whole group of CMD and bruxing 
Table 1. Mean age, standard deviation (SD) and range in the four groups of CMD patients presenting with mild, moderate, severe and extreme bruxing behavior.

\begin{tabular}{|l|l|l|l|l|l|}
\hline All group & Mild & Moderate & Severe & Extreme & Total \\
\hline $\mathrm{N}$ & 20 & 32 & 36 & 20 & 108 \\
\hline Mean age & 33.0 & 30.65 & 33.2 & 34.05 & 33.3 \\
\hline SD & 10.81 & 10.66 & 9.47 & 12.15 & 10.78 \\
\hline Range & $14-67$ & $14-63$ & $16-47$ & $16-67$ & $14-55$ \\
\hline
\end{tabular}

Table 2. Mean level of anxiety, standard deviation(SD) and range in the mild, moderate, severe and extreme subgroups of CMD and bruxing behavior patients.

\begin{tabular}{|l|l|l|l|l|}
\hline & Mild & Moderate & Severe & Extreme \\
\hline $\mathrm{N}$ & 20 & 32 & 36 & 20 \\
\hline Mean TMAS & 13.61 & 13.8 & 13.48 & 17.22 \\
\hline SD & 3.96 & 5.09 & 5.18 & 4.92 \\
\hline Range & $7-20$ & $5-25$ & $0-23$ & $6-25$ \\
\hline
\end{tabular}

Nonparametric ANOVA Kruskall-Wallis test : 0.05

Table 3. Mean level of pain, standard deviation(SD) and range in the four subgroups of patients presenting mild, moderate, severe and extreme bruxing behavior.

\begin{tabular}{|l|c|c|c|c|}
\hline & Mild & Moderate & Severe & Extreme \\
\hline $\mathrm{N}$ & 20 & 32 & 36 & 20 \\
\hline $\begin{array}{l}\text { Mean level } \\
\text { of Pain }\end{array}$ & 4.1 & 5.15 & 5.5 & 5.4 \\
\hline $\mathrm{SD}$ & 3.06 & 3.19 & 2.69 & 1.57 \\
\hline Range & $0-9$ & $0-9$ & $0-8.5$ & $0-8.5$ \\
\hline
\end{tabular}

Kruskall-Wallis test: 0.27 (not significant)

Table 4. Levels of anxiety, standard deviation(SD) and range, when the group of CMD and bruxing behavior patients was reclassified in subgroups presenting pain in 1-3, 4-6, 7-9, 10-12 anatomic sites.

\begin{tabular}{|l|l|l|l|l|}
\hline & $\begin{array}{l}\mathbf{1 - 3} \\
\text { painful } \\
\text { sites }\end{array}$ & $\begin{array}{l}\mathbf{4 - 6} \\
\text { painful } \\
\text { sites }\end{array}$ & $\begin{array}{l}\mathbf{7 - 9} \\
\text { painful } \\
\text { sites }\end{array}$ & $\begin{array}{l}\mathbf{1 0 - 1 2} \\
\text { painful } \\
\text { sites }\end{array}$ \\
\hline TMAS & 11.72 & 14.93 & 14.92 & 16.12 \\
\hline SD & 4.68 & 5.06 & 4.89 & 6.83 \\
\hline range & $0-20$ & $5-25$ & $5-22$ & $9-28$ \\
\hline
\end{tabular}

One way analysis of variance: p: 0.07 (considered not quite significant)

Table 5. Correlational analysis in some specific pair of variables.

\begin{tabular}{|l|l|l|l|}
\hline Pair of variables & $\begin{array}{l}\text { Pearson } \\
\text { Product }\end{array}$ & p-value & Significance \\
\hline Level of pain-Anxiety & r: 0.05 & 0.57 & not significant \\
\hline Painful sites-anxiety & r: 0.2164 & 0.02 & significant \\
\hline $\begin{array}{l}\text { Severity of bruxism- } \\
\text { anxiety }\end{array}$ & r: 0.1861 & 0.05 & significant \\
\hline $\begin{array}{l}\text { Severity of bruxism- } \\
\text { pain sites }\end{array}$ & r: 0.5509 & 0.0001 & $\begin{array}{l}\text { extremely } \\
\text { significant }\end{array}$ \\
\hline
\end{tabular}

Table 6. Different levels of anxiety (mean, standard deviation - SD and range) in 108 bruxers and CMD patients.

\begin{tabular}{|l|c|c|c|c|c|c|}
\hline & $\begin{array}{c}\text { No } \\
\text { anxiety }\end{array}$ & Mild & Moderate & Severe & Extreme & Totals \\
\hline & $0-3$ & $4-7$ & $8-14$ & $15-21$ & $22-28$ & \\
\hline $\mathrm{N}$ & 1 & 7 & 50 & 42 & 8 & 108 \\
\hline mean & & 6 & 11.2 & 17.81 & 23 & \\
\hline SD & & 0.81 & 1.93 & 1.88 & 1.48 & \\
\hline range & & $5-7$ & $8-14$ & $15-21$ & $22-25$ & \\
\hline
\end{tabular}

behavior (33.0 years) was very similar to the mean age reported in other studies ${ }^{18,2}$.

Mean level of anxiety: The mean levels of anxiety in the mild, moderate, severe and extreme group of CMD and bruxing behavior were about 13.61, 13.8, 13.48 and 17.22 respectively. The mean level of anxiety was not different in the mild, moderate and severe groups of bruxing behavior patients, but was statistically different and significant from the extreme to the severe group of CMD and bruxing behavior patients (Kruskall Wallis non parametric test, $p<0.05$ )

Mean level of pain: The mean level of pain was about 4.1 in the mild group, 5.15 in the moderate group, 5.5 in the severe group and 5.4 in the extreme group. Even though, the severity increased from the mild to the severe group, this difference was not statistically significant (Kruskal-Wallis test p:0.27).

Anxiety in patients presenting with 1-3, 4-6, 7-9, and 10-12 painful sites: The TMAS score was about 11.72 in the mild group presenting 1-3 painful sites, 14.93 in the group presenting 4-6 painful sites, 14.92 in the group presenting 7-9 painful sites and 16.12 in the group presenting 10-12 painful sites. Because parametric ANOVA test demonstrated that the $p$ value was about 0.0713 , the difference in anxiety levels in the four groups was considered not significant.

Correlational analysis using Pearson Product Moment correlation: We looked for further information about putative additional relationships between variables of interest. In order to carry out this, we used Pearson correlation to establish values between pairs of variables. We found a positive correlation between the level of pain and anxiety as Pearson Product moment Correlation Coefficient was about r:0.05 and p:0.57 but such a correlation was weak and non-significant. On the other hand, we found a positive and significant correlation between painful sites and anxiety as r: 0.2164 and p:0.02. We also found a positive and significant correlation between levels of bruxism and anxiety (r:0.1861, p:0.05). The mean severity of bruxing behavior in $108 \mathrm{CMD} /$ bruxing behavior patients was about 10.78 indicating that moderate and severe cases of bruxing behavior predominated in this 
sample of 108 patients. We also found a positive correlation between the severity of bruxing behavior and painful sites (Pearson correlation $r=0.5509$ and $p<0.0001$ ), and this correlation was considered extremely significant. These data indicate that the correlation between severity of bruxing behavior/ painful sites was the strongest of all. Clinical and epidemiological implications of these results will be further explored in another study.

\section{DISCUSSION}

Mean level of anxiety: The mean level of anxiety in the group of $108 \mathrm{CMD}$ and bruxing behavior patients was about 14.52. We found a mean level of anxiety of about 13.6, 13.8, 13.48 and 17.22 in the groups presenting with mild, moderate, severe and extreme bruxing behavior. The extreme bruxing behavior group showed the highest level of anxiety. The mean level of anxiety was not different in the mild, moderate and severe groups of bruxing behavior patients, but was statistically different and significant from the extreme to the severe group of CMD and bruxing behavior patients. The results of this study are in accordance with one research ${ }^{19}$ in which investigators observed that tooth wear patients presented significantly more trait anxiety than controls. However, it would we be wise to carry out a study to evaluate if those who present with advanced wear are in fact extreme bruxers. Because we observed that different levels of anxiety were present only from the extreme to the severe groups of bruxers, the results of this study are supported by another study reporting that even when the TMD patients are subdivided along a continuum of severity, there still do not appear to be any major psychological difference between the TMD patients and other groups ${ }^{20}$.

Further support for our study comes from another research ${ }^{21}$ in orofacial pain patients demonstrating that the self report of depression and anxiety showed no significant differences among the diagnostic subgroups. Most patients in that study ${ }^{21}$ were bruxers, but researchers did not include a extreme group in terms of bruxing behavior and severity of internal joint derangements. Reports in the literature suggesting that extreme groups of bruxing behavior presenting with severe clinical symptoms associated to the behavior, do exist ${ }^{6,22}$.

Mean level of pain: The mean level of pain in the group of $108 \mathrm{CMD} /$ bruxing behavior patients we studied was about 5.03, indicating that most CMD and bruxing behavior patients in our study presented with moderate pain for initial consultation. Therefore the results of our study are very similar to one investigation ${ }^{23}$ about pain and quality of life in CMD patients demonstrating that most patients presented with moderate pain at initial consultation.

Additionally, one investigation ${ }^{4}$ found that most CMD and bruxing behavior patients presented with severe pain, but researchers in that study included only severe and longstanding bruxers in their study, whereas we included subgroups of mild, moderate, severe and extreme groups of bruxers. The use of different subgroups may account for a different severity of pain report. The levels of pain in the mild, moderate, severe and extreme groups of bruxers were 4.1, 5.1, 5.5 and 5.4 and the difference was not statistically significant.

Anxiety and pain in single and multiple sites: The mean levels of anxiety in the group presenting with pain in 1-3 sites, 4-6 sites, 7-9 sites and 10-12 anatomic sites were about $11.72,14.93,14.92$ and 16.12 respectively. The level of anxiety increased with the number of painful sites and the difference was almost statistically significant. This means that the relationship between anxiety and number of painful sites is not so significant. However, the results of this study agree with one investigation that reported that increased psychic distress including depression/ anxiety was observed among persons reporting pain at multiple sites $^{24}$.

Levels of pain and anxiety, painful sites and anxiety, severity of bruxism and anxiety, severity of bruxism and painful sites. Because the relationship between psychophysiological variables and pain has been considered traditionally complex, we further studied such relationships using correlational analysis. The correlation coefficient between level of pain and anxiety was r:0.05 and the p value was 0.57 and therefore it was considered not significant. The correlation between painful sites and anxiety was $r=0.2164$ and $p=0.02$, consequently, it was considered significant, the correlation coefficient between severity of bruxism and anxiety was $r=0.1861, p=0.05$ and thus it was considered statistically significant. Finally, the correlation coefficient between severity of bruxing behavior and number of pain sites was $r=0.5509$ and $p=0.0001$, and so it was considered extremely significant. To conclude, the correlations between painful sites and anxiety and between severity of bruxing behavior and pain sites were the strongest from a statistical point of view and therefore, the results of our investigation agree with one study ${ }^{24}$ correlating depression and anxiety with pain in multiple sites and with another investigation ${ }^{22}$ reporting more severe pain and pain in multiple sites in more severe bruxers. Follows a summary of major findings in our study:

1. Mean level of anxiety increased with the severity of bruxism but the difference was statistically significant only from the extreme to the severe group of bruxers.

2. The mean level of pain was moderate: 5.5

3. Anxiety increased with the number of painful sites

4. The level of pain correlated positively with the level of anxiety but the correlation was weak

5. Painful sites and anxiety were positive and significantly correlated as p:0.02. 
6. Severity of bruxing behavior correlated positively and significantly with the number of painful sites, p:0.0001.

\section{CONCLUSIONS}

Based on data, statistical analysis and review of the literature, it seems wise to draw the following conclusions:

1. The mean level of anxiety did not change significantly among the subgroups of mild, moderate and severe bruxers, however, the extreme group of bruxers and CMD patients presented with the highest level of anxiety and the difference was statistically significant.

2. Most CMD and bruxing behavior patients presented with a moderate level of pain

3. The levels of anxiety in subgroups presenting with different pain sites were different, but the difference was statistically significant.

4. Moderate and severe levels of anxiety predominated in this set of CMD and bruxing behavior patients.

5. The strongest correlation was between number of painful sites and severity of bruxing behavior.

\section{REFERENCES}

1. May R. O significado da ansiedade. Rio de Janeiro. São Paulo: Zahar Editores, 1977, 1-374

2. Molina O, dos Santos J, Nelson S, Nowlin T. A clinical study of specific signs and symptoms of cranio mandibular disorders in bruxers classified by the degree of severity. J Craniom Pract 1999; 17:368-379.

3. Molina O, dos Santos J, Nelson S, Grossman E. Prevalence of modalities of headaches and bruxism among patients with craniomandibular disorders. J Craniom Pract 1997; 15: 314-325.

4. Kampe T, Edman G, Bader G, Tagdae T, Karlsson, S. Personality traits in a group of subjects with longstanding bruxing behavior. J Oral Rehab 1997 24: $588-593$

5. Dao T, Lund J, Lavigne G. Comparison of pain and quality of life in bruxers and patients with myofascial pain of the masticatory muscles. J Orofac Pain 1994; 8: 350-356.

6. Ware J, Rugh J. Destructive bruxism: Sleep stage relationships. Sleep 1988; 11: 172-181.

7. Olkinuora M. A psychosomatic study of bruxism with emphasis on mental strain and familiar predisposition factors. Procc Finn Dent Soc 1972; 68 110-123.

8. Freud S. Obras completas. Tomo III. Tercera Edición, Madrid, 1973: 33793423

9. Moulton R. Psychiatric considerations in maxillofacial pain. JADA 1955; 51: 408-416

10. Greene C, Olson R, Laskin D. Psychological factors in the etiology, progression and treatment of MPDS. JADA 1982; 105: 443-448.

11. Malow R, Grimm L, Olson R. Differences in pain perception between myofascial pain dysfunction patients and normal subjects. J Psychosom Res 1980; 24: 303-309

12. Mutlu N, Herken H, Güray E, Öz F, Kalayci A. Evaluation of the prevalence of temporomandibular joint disorders syndrome in dental school students with psychometric analysis. Turk J Med Scienc 2002; 32: 345-350.
13. Phillips J, Gatchel R, Wesley A, Ellis E. Clinical implications of sex in acute temporomandibular disorders. JADA 2001; 132: 49-57.

14. Meldolesi G, Picardi A, Accivile E, Toraldo R, Biondi M. Personality and psychopathology in patients with temporomandibular joint-pain dysfunction syndrome: A controlled investigation. Psychotherapy and Psychosomatics 2000; 69: 322-328.

15. Heiberg A, Helöe B, Krögstad B. The myofascial pain dysfunction: Dental symptoms and psychological and muscular function: An overview. Psychother Psychosom 1978; 30: 81-87

16. Eggen S. Nevromuskulaer spenning some arsak til kveveleddslidelser Norske Tannlaegefore Tid 1954; 4:123-131

17. Taylor J. A personality scale of manifest anxiety. J Abnorm Soc Psychol 1953 48: 87-90

18. Serralta F, de Freitas P. Bruxismo e afetos negativos: Um estudo sobre ansiedade, depressão e raiva em pacientes bruxômanos. J Bras Oclus ATM Dor Orof 2002; 2: 19-22.

19. Dasilva A, Oakley D, Hemmings K, Newman H, Watkins S. Psychosocia factors and tooth wear with a significant component of attrition. Europ $J$ Prosth and Rest Dent 2001; 86:195-102.

20. Epker J, Gatchel R, Ellis E. A model for predicting chronic pain. JADA 1999 130:1470-1475.

21. Harness D, Donlon W, Eversole L. Comparison of clinical characteristics in myogenic TMJ-ID and AFP patients. Clin J Pain 1990; 6: 4-17.

22. Boutros N, Montgomery M, Nishioka G, Hatch J. The effects of severe bruxism on sleep architecture: A preliminary report. Clin Electroencephal 1993, 24: 59-62.

23. Murray $\mathrm{H}$, Locker $\mathrm{D}$, Mock D, Tenenbaum $\mathrm{H}$. Pain and quality of life in patients referred to a craniofacial unit. J Orofac Pain 1996; 10: 316 323

24. Von Korff M, Wagner E, Dworkin S, Saunders K. Chronic pain and use of ambulatory health care. Psychos Med 1991; 53: 61-79. 